\title{
Hard Photonic Glasses and Corundum Nanostructured Films from Aluminothermic Reduction of Helicoidal Mesoporous Silicas
}

\author{
Thanh-Dinh Nguyen, ${ }^{a}$ Wadood Y. Hamad, ${ }^{b}$ and Mark J. MacLachlan ${ }^{a, *}$
}

\begin{abstract}
${ }^{a}$ Department of Chemistry, University of British Columbia, 2036 Main Mall, Vancouver, British Columbia, V6T 1Z1, Canada

${ }^{b}$ FPInnovations, 2665 East Mall, Vancouver, British Columbia, V6T 1Z4, Canada

*Corresponding Author: mmaclach@chem.ubc.ca
\end{abstract}

\section{Experimental Section}

Chemicals: Tetramethoxysilane $\left(\mathrm{Si}\left(\mathrm{OCH}_{3}\right)_{4}, \geq 99 \%\right.$, Sigma-Aldrich), aluminum foil (Alcan), hydrochloric acid, and sodium hydroxide were received from standard suppliers. Cellulose nanocrystals (CNCs) were prepared as previously described from sulfuric acid hydrolysis of fully-bleached, commercial kraft softwood pulp. ${ }^{1,2}$

Structural characterization: Powder X-ray diffraction (PXRD) patterns of the samples were recorded on a D8 advance X-ray diffractometer $(\lambda=1.540 \AA)$. UV-vis transmission spectroscopy was conducted on a Cary 5000 spectrophotometer. Circular dichroism (CD) experiments were recorded using a JASCO J-710 spectropolarimeter. Polarized optical microscopy (POM) with crossed polarizers was performed on an Olympus BX41 microscope. Scanning electron microscopy (SEM) images of the samples were obtained on a Hitachi S4700 electron microscope. Samples were prepared by breaking films into small pieces and attaching them to aluminum stubs using double-sided adhesive tape and sputter coating with gold $(5 \mathrm{~nm})$. Energydispersive X-ray (EDX) analysis was collected using a Hitachi S2300 scanning electron microscope. XPS measurements were achieved in an ion-pumped chamber (evacuated to $10^{-9}$ Torr) of a photoelectron spectrometer (Leybold MAX200) equipped with a focused Al $\mathrm{K}_{\alpha} \mathrm{X}$-ray source. Thermogravimetric analyses (TGA) of the films $(\sim 1.0 \mathrm{mg})$ were conducted at a heating rate of $10{ }^{\circ} \mathrm{C} \mathrm{min}{ }^{-1}$ under air to $850{ }^{\circ} \mathrm{C}$ using a PerkinElmer Pyris 6 thermogravimetric analyzer. Infrared spectra were obtained on neat samples using a Nicolet 6700 FT-IR equipped with a Smart Orbit diamond attenuated total reflectance (ATR) attachment. Gas adsorption experiments were conducted on a Micromeretics Accelerated Surface Area \& Porosity (ASAP) 2020 system. Samples $(\sim 120 \mathrm{mg})$ were degassed at $150{ }^{\circ} \mathrm{C}$ in vacuum for $4 \mathrm{~h}$ before measurements. Hardness testing was performed on a MicroMet 6030 microdurometer to measure the mechanical hardness 
of the samples using Vickers hardness test apparatus. The load applied was $100 \mathrm{mN}$. Tensile tests were conducted on a Universal Testing machine (Shimadzu AGS-X) at a cross-head speed of $0.5 \mathrm{~mm} / \mathrm{min}$. Specimens were cut into strips of average size $0.66 \times 1.0 \mathrm{~cm}$ in both directions that were clamped to the jigs for testing. Stress-strain curves were generated from loaddisplacement data. A minimum of three specimens were prepared and tested for each condition using a 500N load cell. Data were analyzed by One-Way ANOVA or t-Test where appropriate followed by a post test such as Tukey's HSD test when necessary.

\section{Captures and Figures}

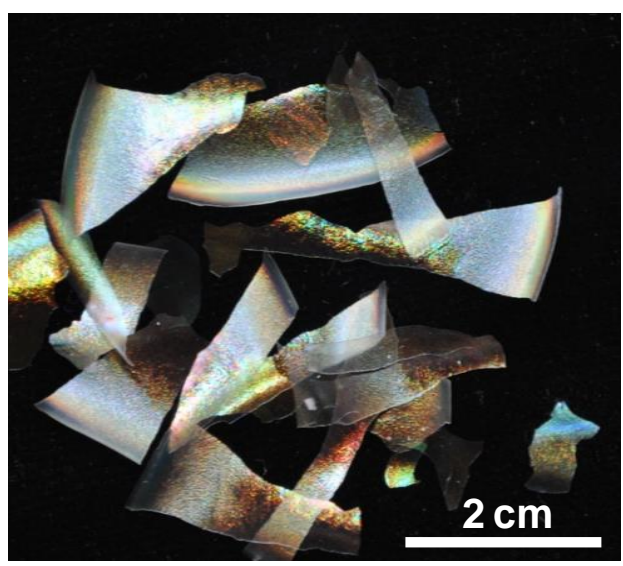

Figure S1. Photograph of CNMS.

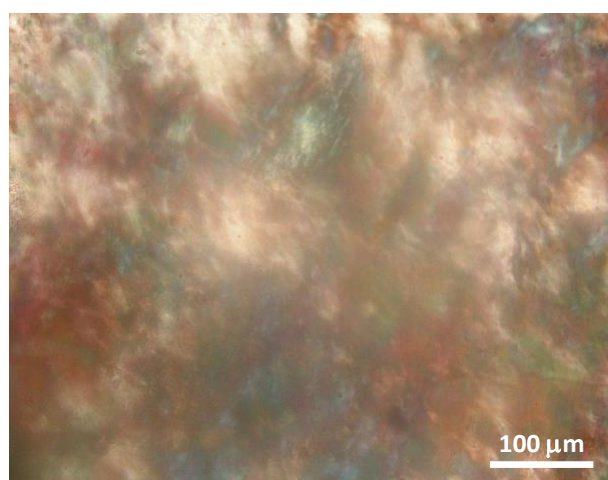

Figure S2. POM image of hardened CNMS. 
a)

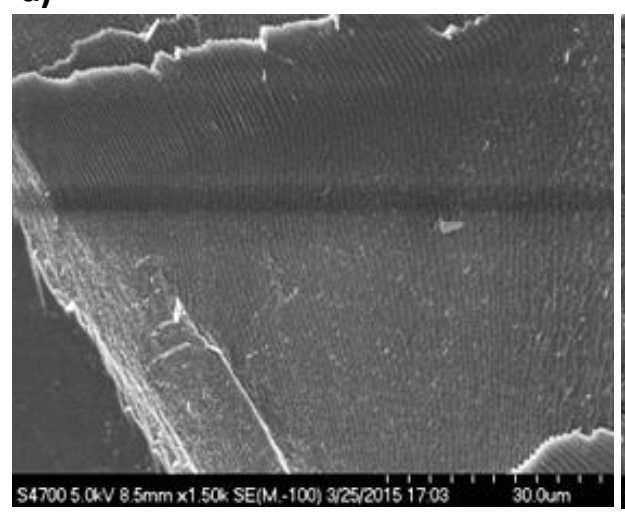

b)

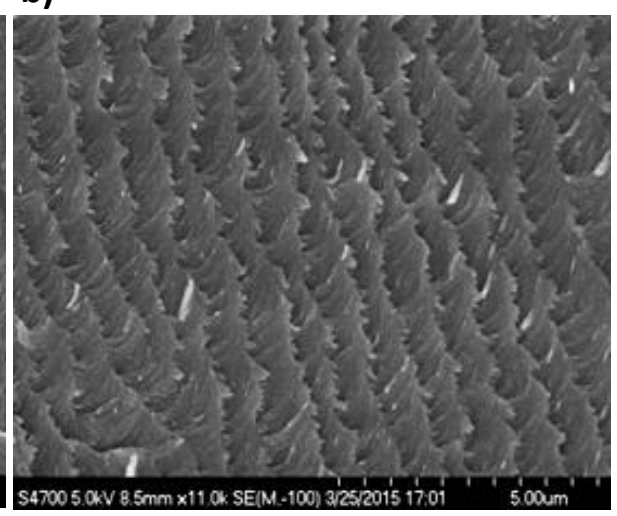

Figure S3. SEM images viewed along fracture cross sections of hardened CNMS.
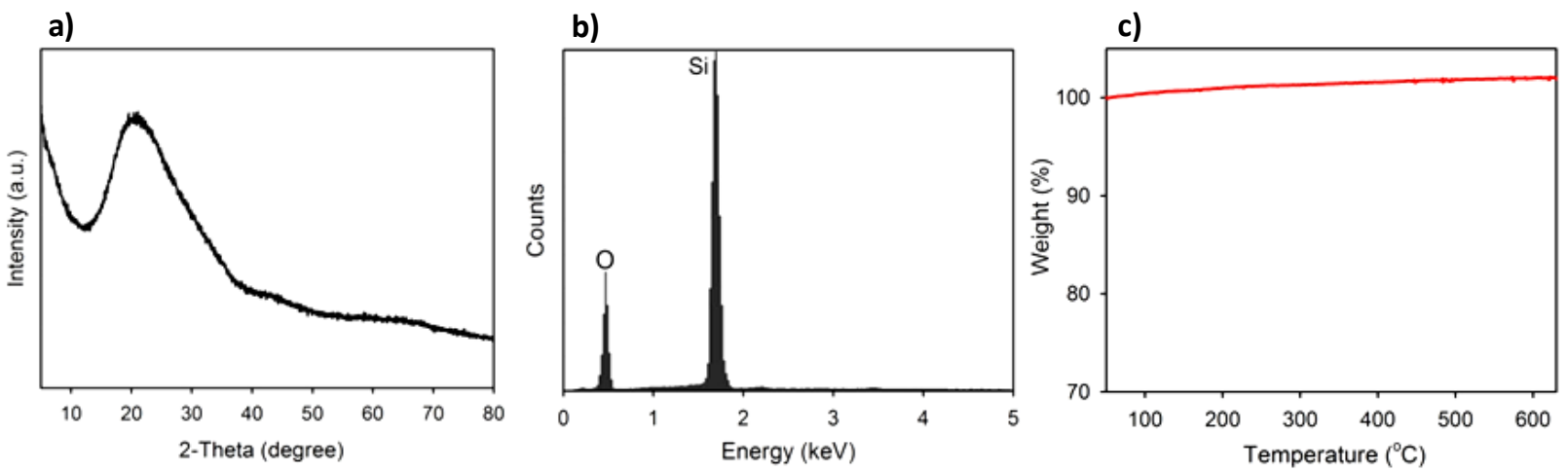

Figure S4. (a) PXRD pattern, (b) EDX spectrum, and (c) TGA curve (air, $10{ }^{\circ} \mathrm{C} \mathrm{min}-1$ ) of hardened CNMS.
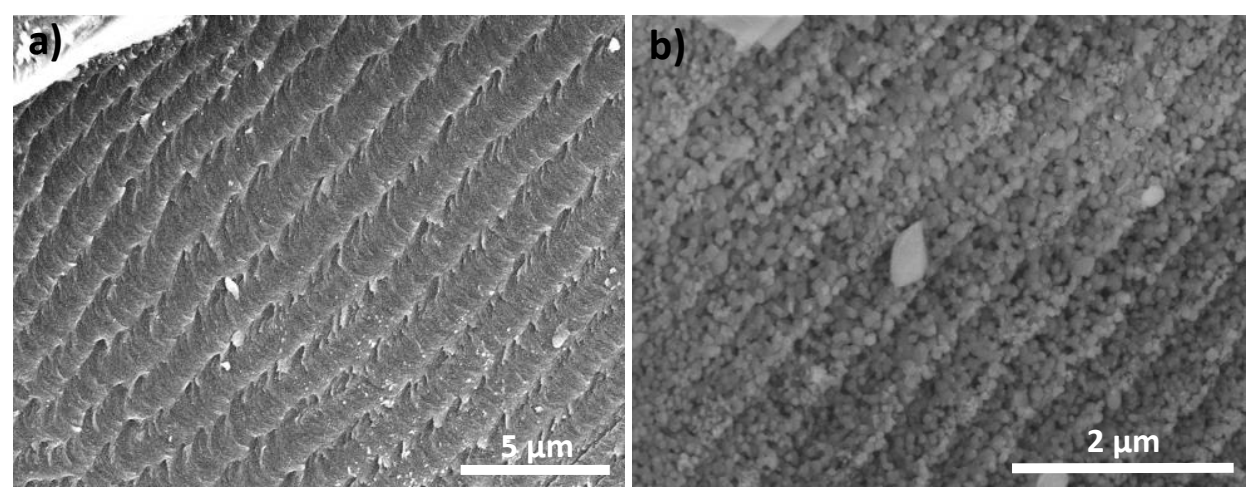

Figure S5. Expanded SEM images with higher magnification viewed along fracture cross sections of a heterogeneous mixture of the reduced films: (a) view of the crosslinked region (transparent) of hardened CNMS and (b) view of the reduced region (dark blue) of alumina/silicon composites. 

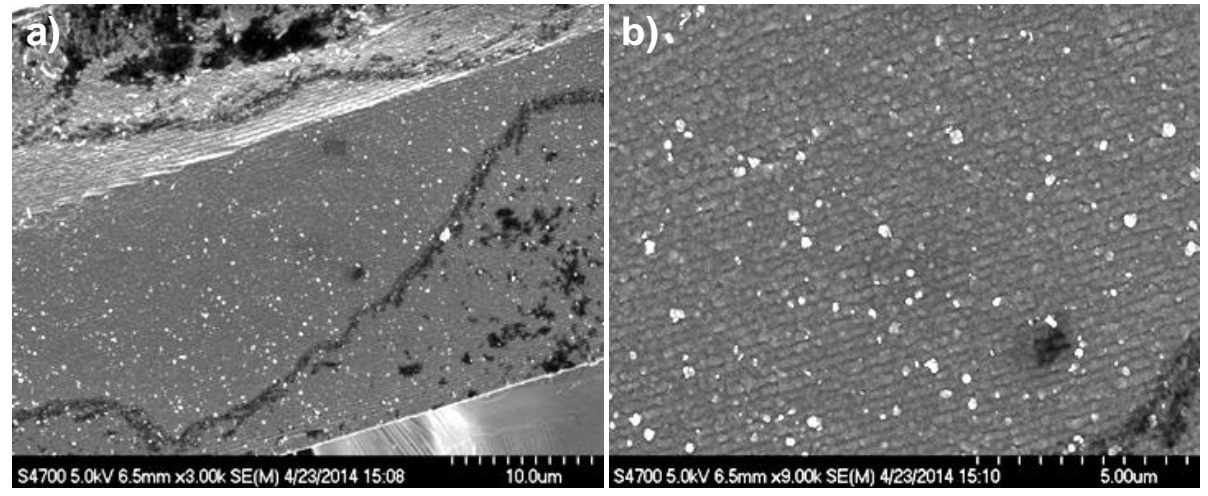

Figure S6. SEM images viewed along cutting edges (a) and fracture cross sections (b) of alumina/silicon composites.

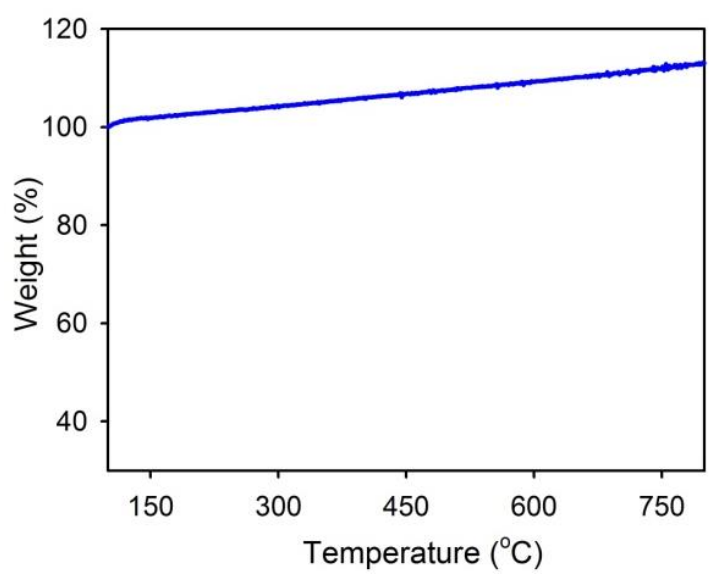

Figure S7. TGA curve of alumina/silicon composites (air, $10^{\circ} \mathrm{C} \mathrm{min}^{-1}$ ). 
a)

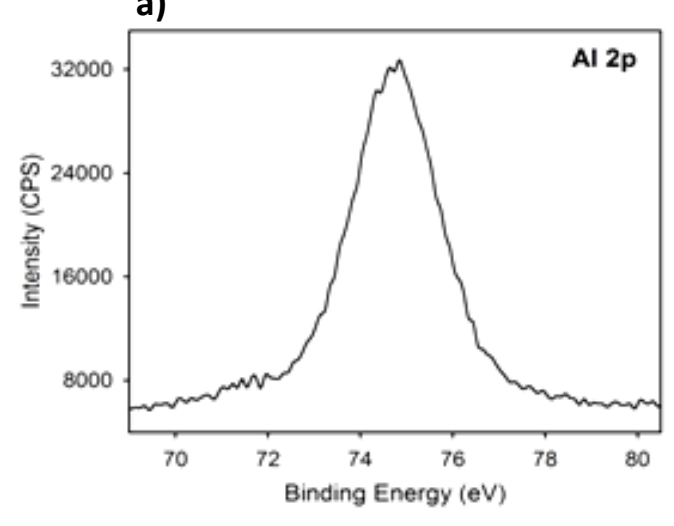

b)

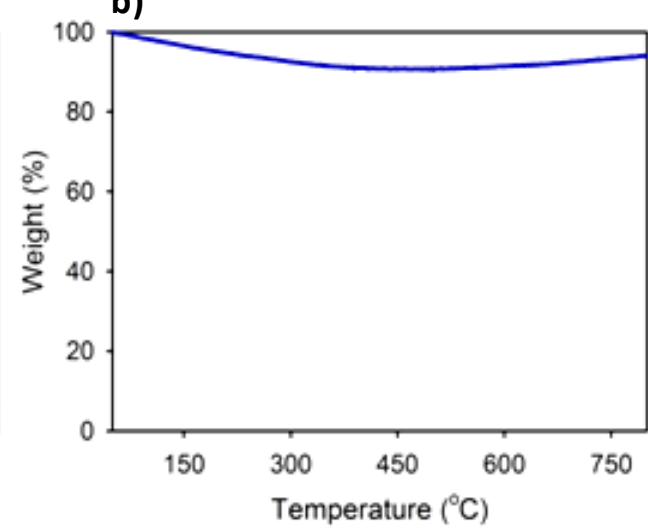

Figure S8. (a) Al $2 p$ XPS spectrum and (b) TGA curve (air, $10{ }^{\circ} \mathrm{C} \min ^{-1}$ ) of mesoporous alumina films.

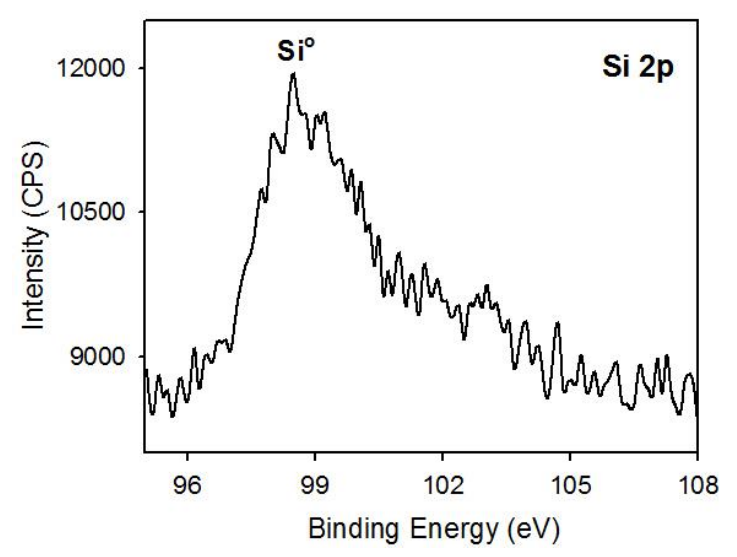

Figure S9. Si $2 p$ XPS spectrum of alumina/silicon composites. 
Figure S10. POM image of mesoporous alumina films.
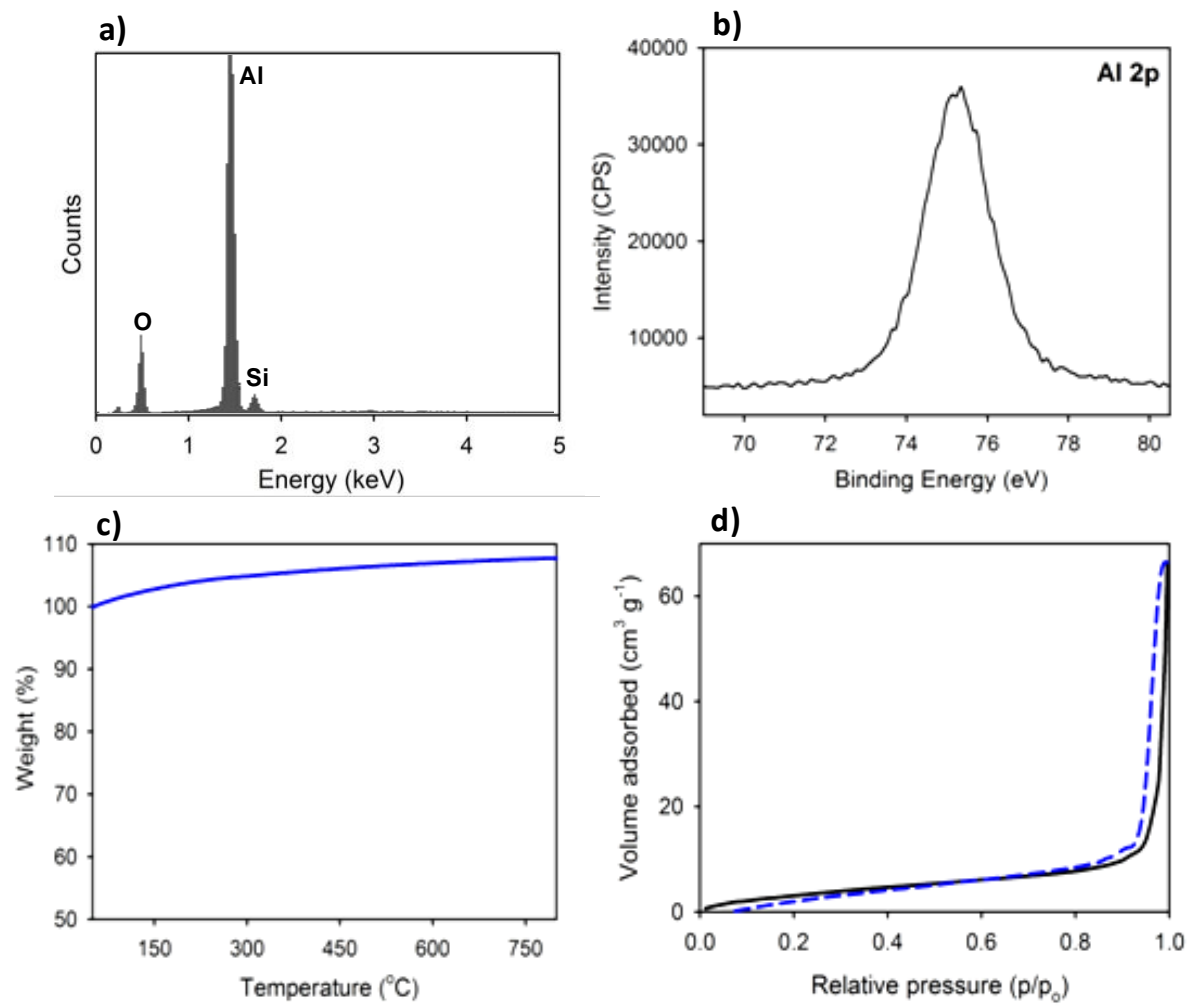

Figure S11. (a) EDX spectrum, (b) Al $2 p$ XPS spectrum, (c) TGA curve (air, $10{ }^{\circ} \mathrm{C} \mathrm{min}^{-1}$ ), and (d) Nitrogen adsorption-desorption isotherms (adsorption $=$ solid, desorption $=$ dashed) of mesoporous silicon/corundum composites. 

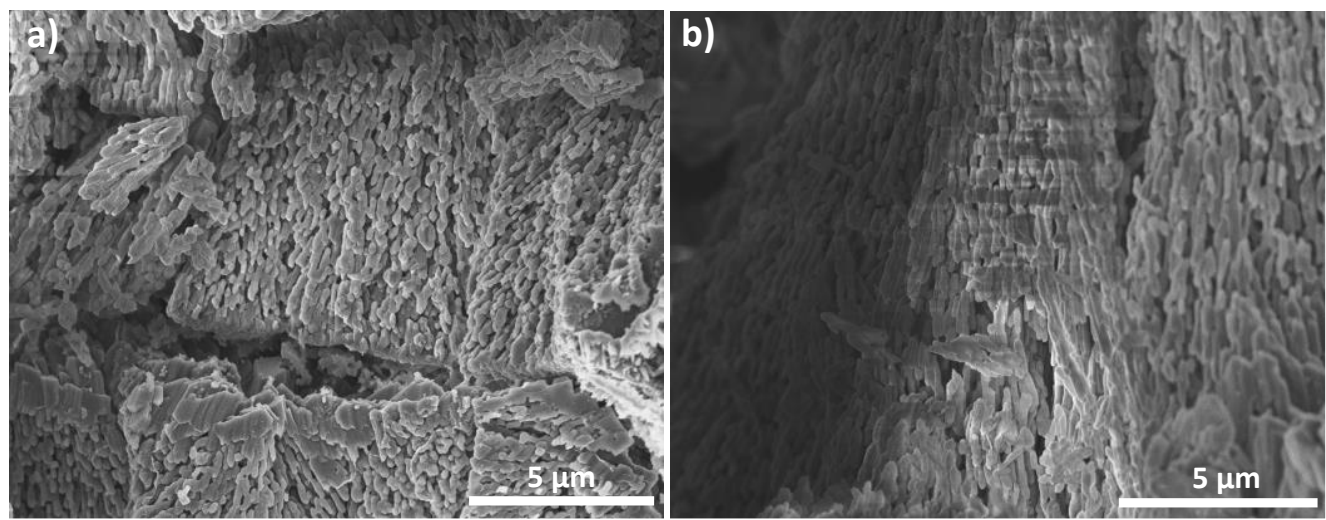

Figure S12. Expanded SEM images of mesoporous corundum films.
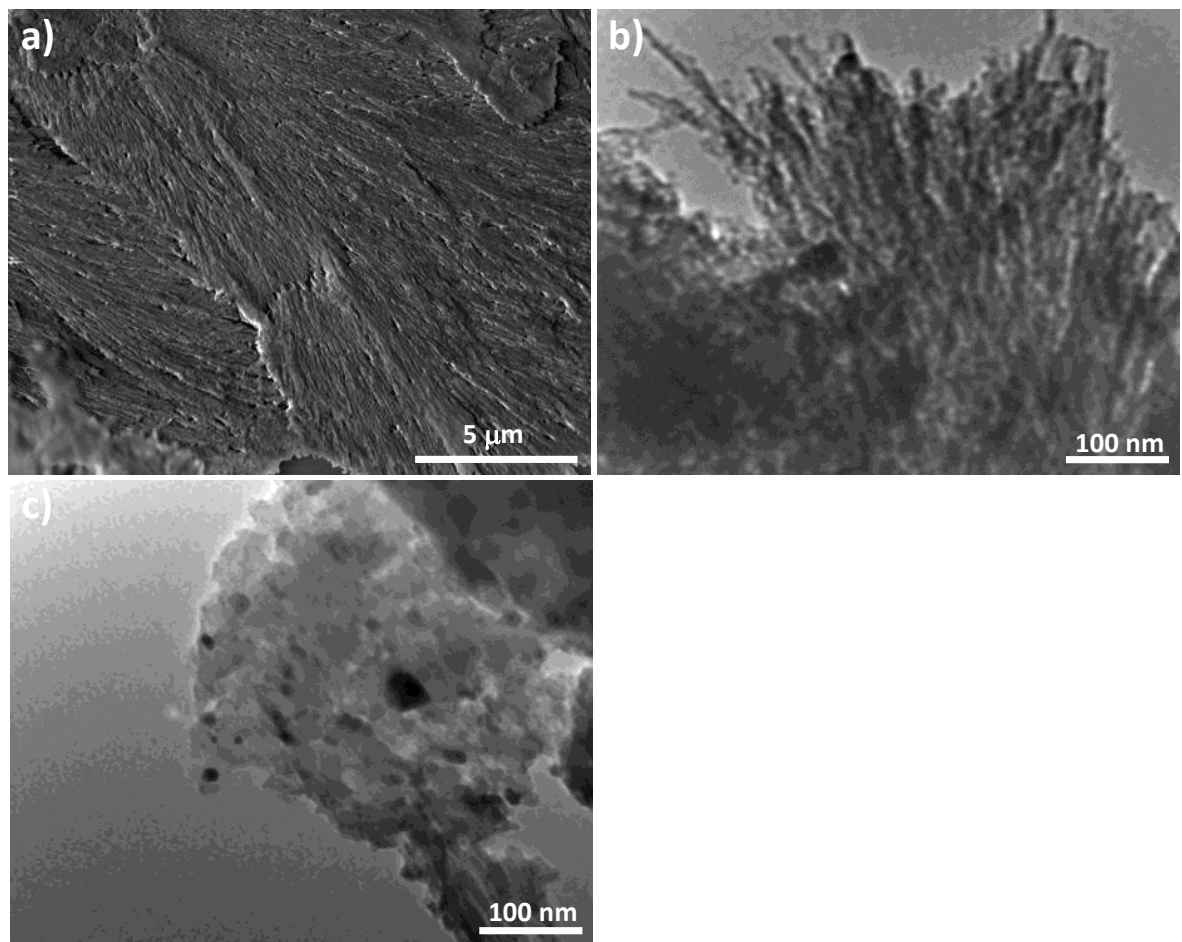

Figure S13. Expanded SEM image and TEM images of mesoporous corundum/silicon composites.

\section{References}

(1) Shopsowitz, K. E.; Qi, H.; Hamad, W. Y.; MacLachlan, M. J. Free-standing Mesoporous Silica Films with Tunable Chiral Nematic Structures. Nature 2010, 468, 422-425.

(2) Hamad, W. Y.; Hu, T. Q. Structure-process-yield interrelations in nanocrystalline cellulose extraction. Can. J. Chem. Eng. 2010, 88, 392-402. 